\title{
Pléyade
}

\section{REVISTA DE HUMANIDADES Y CIENCIAS SOCIALES}

número 24 | julio-diciembre 2019

online ISSN 07 19-3696 / ISSN 07 18-655x

\section{Alejandra Bottinelli}

Marcelo Sanhueza

Margarita Pierini

Patricia Espinosa H.

Jaime Ginzburg

Karen Saban

Miguel Enrique Morales

Gustavo Eduardo Carvajal

Bernardo Rocco Núñez

Federico Zurita Hecht

Mary Luz Estupiñán Serrano

Clara María Parra Triana

raúl rodríguez freire

Ana Pizarro

José Leandro Urbina

Javier González Arellano

Hugo Herrera Pardo

\section{INTRODUCCIÓN}

Literatura y política en América Latina en el siglo XX: apuntes para una discusión

\section{INTERVENCIÓN}

Mafalda en tiempos de terrorismo de Estado: los códigos de una imagen

\section{Artículos}

Política de la posmemoria en la narrativa chilena

Literatura y política en Bernardo Kucinski

Rodolfo Walsh, antecedente de la novela testimonial latinoamericana. Sobre la matriz narrativa policial en Operación masacre

Vargas Llosa y la modernidad política latinoamericana: ¿Quijote de la libertad o gesticulista del statu quo?

Violencia, género y memoria en El desierto (2005) de Carlos Franz

Microespacios de ejercicio de la violencia cultural de Pinochet en Bello futuro y

La Victoria de Gerardo Oettinger

Latinoamericanismo de la descomposición: una lectura de su crítica y de su crisis

\section{ENTREVISTAS}

Ana Pizarro: la reina del Amazonas

\section{RESEÑAS}

Ana Cristina Benavides González. La soledad de Macondo o la salvación por la memoria. Bogotá: Siglo del Hombre Editores, 2014. 288 pp. ISBN

9789586652766

Alejandro Fielbaum. Los bordes de la letra. Ensayos sobre teoría literaria latinoamericana en clave cosmopolita. Leiden: Almenara editorial, 2017. 332 pp. ISBN 9789492260185 


\title{
Microespacios de ejercicio de la violencia cultural de Pinochet en Bello futuro y La Victoria de Gerardo Oettinger Microspaces of deployment of Pinochet's Cultural Violence in Bello futuro and La Victoria by Gerardo Oettinger
}

\author{
Bernardo Rocco Núñez \\ Universidad Alberto Hurtado \\ Federico Zurita Hecht \\ UnIVERSIDAD Finis Terrae
}

\begin{abstract}
Resumen
El artículo examina los dramas Bello futuro (2013) y La Victoria (2014) de Gerardo Oettinger. Las obras estudiadas realizan una representación realista en un tiempo en que esta tendencia estética no es dominante en la producción dramática chilena actual, con el propósito de cartografiar los microespacios donde la dictadura cívicomilitar de Pinochet ejerció su poder. Esta forma de representación recurriría a una fenomenología del hambre como rasgo distintivo del despliegue del poder dictatorial en la historia de Chile. Para esto, los dramas se enfocan en la representación de la vida cotidiana de los sujetos que experimentan marginalidad económica, política y de género producida por la dictadura, y en cómo ésta busca el adoctrinamiento ideológico de las mujeres con el fin de mantener intacto el ejercicio de su poder. El interés de revisar las expresiones de violencia y marginación producidas por la dictadura en los dramas de Oettinger se sustenta en la necesidad de construir una imagen sobre el origen de la violencia cultural que caracteriza a la sociedad chilena.
\end{abstract}

Palabras clave: Realismo; Microespacios; Dictadura; Fenomenología; Marginalidad. 


\begin{abstract}
The article examines the dramas Bello futuro (2013) and La Victoria (2014) by Gerardo Oettinger. These works portray a realistic representation at a time when such aesthetic trend was not dominant within Chile's dramatic production, with the purpose of mapping the microspaces where Pinochet's military-civic dictatorship exercised its power. This form of representation would resort to a phenomenology of hunger as a distinctive feature of the deployment of dictatorial power in Chilean history. For doing this, the dramas focus on the representation of the daily life of the subjects who experience economic, political and gender marginality produced by the dictatorship, and on how it seeks the ideological indoctrination of women in order to keep the exercise intact of his power. The interest in reviewing the expressions of violence and marginalization that the dictatorship produced in Oettinger's dramas is based on the need to build an image of the origin of Chile's characteristic contemporary cultural violence.
\end{abstract}

Keywords: Realism; Microspaces; Dictatorship; Phenomenology; Marginality. 
Los dramas Bello futuro (2013) y La Victoria (2014) de Gerardo Oettinger escarban en los sedimentos que constituyen el origen de la violencia cultural manifestada en la desigualdad social del Chile neoliberal y su persistencia actual. La violencia directa producida por el golpe de Estado de 1973 y la violencia estructural resultante de la dictadura cívico militar ha derivado, a partir del modelo económico neoliberal impuesto por la dictadura de Pinochet, en una desigualdad social que los dramas de Oettinger abordan mediante la representación realista de los microespacios sociales de violencia cultural propios de esa época. Tal enfoque realista sobre el pasado reciente chileno corresponde a una forma particular de representación por medio de la cual "la realidad objetiva se refleja (...) como realmente es [y donde] la cuestión de la totalidad juega un papel decisivo". Al respecto, ambas obras son el resultado del extenso trabajo de recopilación que Oettinger realizó basado en los testimonios de un grupo de mujeres, exponiendo la derrota mediante el contraste de la realidad ficticia heroica y la realidad referencial violenta de los sujetos marginales.

Se plantea en este contexto que la forma de representación realista utilizada por Oettinger recurre a una fenomenología del hambre como rasgo distintivo del despliegue del poder dictatorial en la historia chilena. La forma de representación realista utilizada por Oettinger se presenta así como necesaria para referir la violencia manifestada por la desigualdad social en el Chile que crea la dictadura militar, a partir de la ejemplificación que constituyen aquellos microespacios sociales donde se ejerció el poder dictatorial. En estas representaciones realistas de los microespacios de la violencia, las estrategias textuales de ambos dramas recurren a la fenomenología del hambre como rasgo distintivo del despliegue del poder en la historia del Chile, un poder refundado por la dictadura militar.

La presencia de esta fenomenología en la estrategia de ambos dramas se vincula de este modo con la resolución de los conflictos mediante la trascendencia de las mujeres violentadas por el sistema social, con el propósito de actuar en contraste con la realidad histórica. De esta forma, la estética realista de Oettinger construye la imagen de una falsa trascendencia de las víctimas en los microespacios de la sociedad chilena con el propósito de potenciar la comprensión de la violencia que, precisamente, impide tal trascendencia y que, por el contrario, origina la derrota de los marginados a manos del modelo económico y su perpetuación como oprimidos. Esta particular fenomenología sobre el hambre se entiende como una experiencia que, en palabras de Ann V. Murphy,

vicia, deshace y compromete el sentido y la intencionalidad de ellas mismas. Interrumpe la experiencia espacial y temporal del sujeto; priva al sujeto de un sentido pre reflexivo de pertenencia al intermundo, de modo que 
se comienza a perder el control de la significación intersubjetivamente constituida, la vida anónima, que ancla e informa la vida en común con los demás².

La experiencia con el hambre al que se exponen diariamente los personajes de ambos dramas compromete la integridad misma del tejido intersubjetivo de sus miembros: la comunidad de mujeres. En este sentido, los dramas acuden específicamente a la representación de dos grupos diferentes de mujeres que viven sumergidas en la inmanencia del hambre, pero que a través de la resistencia a la dictadura trascienden. Sin embargo, no hay que olvidar que tal trascendencia resulta ser falsa, pues el referente histórico de los dramas deviene en la derrota: el fracaso de la vía chilena al socialismo.

Con relación al argumento, la acción en el drama Bello Futuro acontece en una sede de CEMA-Chile durante la crisis económica del año $1982^{3}$. Allí, un grupo de mujeres trabaja en un taller de corte y confección de ropa. La acción gira en torno a la inminente visita de la presidenta de la fundación, Lucía Hiriart, esposa del dictador Augusto Pinochet. El anuncio de su visita desata la tensión entre las integrantes del taller, quienes terminan incendiando la sede.

Por su parte, la acción en la obra La Victoria sucede alrededor de una olla común organizada por un grupo de pobladoras quienes, motivadas por una religiosa, luchan por alimentar a sus familiares, también durante la crisis económica de $1982^{4}$. El drama se desarrolla en la capilla de una población marginal de Santiago, luego de que la policía allanara el lugar. La obra termina con la muerte de la hija de una de las pobladoras en un asalto a un camión que transporta carne.

En ambos dramas, los microespacios de violencia cultural -el taller y la capillarepresentan la expresión máxima de cómo la mecánica del poder sobre el individuo "en su forma capilar de existencia (...) alcanza su cuerpo, se inserta en sus gestos,

2 Ann V. Murphy, "The Will to Live and the Meaning of Life: Hunger as Vulnerability in French Existential Phenomenology", Journal of the British Society for Phenomenology 49, no. 3 (2018): 9. Traducción propia.

3 Centros de Madres CEMA-Chile es una fundación creada en 1954 y en actividad hasta 2016, presidida por Lucía Hiriart durante la dictadura de su esposo Augusto Pinochet. Fue una institución de derecho privado, sin fines de lucro y con presencia en todo Chile. Como institución de tipo paternalista y asistencial, tuvo como propósito fundamental coordinar las actividades de mujeres de escasos recursos a través de las acciones de voluntarias (esposas de militares o partidarios de la dictadura) y orientadas a proporcionar a las socias capacitación técnico-manual, moral e intelectual tendientes a la superación física y espiritual de las mujeres.

4 La obra hace referencia a la población La Victoria, ubicada en la comuna de Pedro Aguirre Cerda en Santiago de Chile, que se formó en 1957 (durante la presidencia de Carlos Ibáñez del Campo) a partir de una toma de terrenos organizada por el Comité de Allegados del Zanjón de la Aguada. La acción de los pobladores se fundó en el principio de que la vivienda es un derecho, y que la solución al problema habitacional pasaba fundamentalmente por la propiedad de un terreno. 


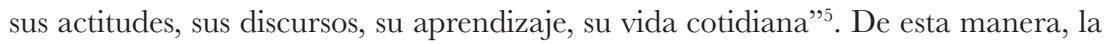
representación de la violencia cultural manifiesta la internalización cotidiana de la desigualdad social chilena, es decir "la esfera simbólica de nuestra existencia (...) que puede usarse para justificar o legitimar la violencia directa o estructural"6.

En un ambiente de precariedad alimentado por el poder represivo de la dictadura, las estrategias de supervivencia que implementan las protagonistas hacen que la representación dramática se enfoque en la inmanencia del hambre. Este enfoque inmanente sobre la vida de un grupo de mujeres durante la dictadura es lo que va articulando una fenomenología del hambre que, a su vez, nutre la doble condición de la mujer como sujeto que simultáneamente afirma y niega la dictadura, en el marco de una economía capitalista patriarcal. La afirmación de la dictadura ocurre porque la mujer es considerada como sujeto responsable de la reproducción biológica y de mano de obra barata, en condiciones laborales de explotación, domesticación y adoctrinamiento, como ocurre en Bello futuro. Pero la negación de la dictadura sucede, asimismo, porque la represión política del régimen militar y la crisis económica generada por el sistema neoliberal autoritario posibilitan el movimiento contrario, la organización de la mujer y su movilización política, como ocurre en La Victoria.

La fenomenología del hambre en los dramas se nutre de la misma inmanencia de lo cotidiano: la temporalidad. En las obras, la pobreza "representa una constricción ineludible del tiempo, fuerza a un sujeto inexorablemente al presente, un presente que se empobrece exactamente debido a esta constricción" ". Es precisamente la constricción del tiempo lo que da pie a la expresión de vulnerabilidad corporal, ontológica y política de las protagonistas. Y es esta misma vulnerabilidad la que permite también, a nivel ficcional, que el desenlace trágico simbolizado por el incendio del taller y la muerte de la niña se transformen en un acto de resistencia que pretende transcender la precariedad cotidiana de la condición humana. En este sentido, el acto de resistencia consiste en ser "vulnerable y luego superar esa vulnerabilidad, al menos provisionalmente, a través de actos de resistencia".

En consecuencia, comprender el fenómeno del hambre no solo como una simple necesidad biológica o deseo extremo sino como una "devastación claramente social" es lo que se pretende a continuación, con el análisis de los dramas. En particular, se busca abrir un espacio de la reflexión que considere la devastación

5 Michel Foucault, Microfísica del poder, Julia Varela y Fernando Álvarez-Uría trads. (Madrid: Las Ediciones de La Piqueta, 1980), 89.

6 Johan Galtung, “Cultural Violence”, Journal of Peace Research 27, no. 3 (1990): 291. Traducción propia.

7 Gayle Salamon, "Here Are the Dogs: Poverty in Theory", Differences: A Journal of Feminist Cultural Studies 21, no.1 (2010):175. Traducción propia.

8 Judith Butler, Vulnerability in Resistance (Durham: Duke University Press, 2016), 12. Traducción propia.

9 Murphy, "The Will to Live", 5. Traducción propia. 
que la dictadura militar chilena causó durante el periodo histórico que los dramas describen, y cómo la violencia cultural derivada de esta devastación social continúa permeando la actualidad chilena.

\section{Carácter realista de la representación}

La producción dramática chilena expone variados ejemplos de desarrollo del realismo en su historia desde la segunda mitad del siglo XIX hasta hoy, a la vez que paralelamente se desarrollan otras propuestas con menor o mayor fuerza. Hasta fines de la década del cincuenta el realismo es la estética dominante, y sus principales exponentes en esos años setenta fueron Daniel Barros Grez, Daniel Caldera, Armando Moock, Germán Luco Cruchaga y Sergio Vodanovic. Pero ya en la década de los sesenta otras propuestas realizadas por Isidora Aguirre, Egon Wolf y Jorge Díaz entre otros, e influenciadas por el teatro épico, el expresionismo, el absurdo y el grotesco, adquieren relevancia en la escritura dramática. Ya en la década de los ochenta, la emergencia del teatro de imagen a cargo de Teatro Fin de Siglo, La Memoria y Teatro del Silencio incide en la escritura para teatro propiciando, por un lado, que el realismo comience a estar ausente tanto en la puesta en escena como en la producción textual, y, por otro, que pierda relevancia la tradicional producción de teatro de texto. Pero en la segunda mitad de la década de los noventa se experimenta una revaloración del texto dramático y un refortalecimiento del teatro de texto, lo que no implica una vuelta a la posición dominante del realismo en Chile. Los primeros dramaturgos que destacan en las dos décadas iniciales del siglo XXI, como Alexis Moreno, Juan Claudio Burgos, Manuela Infante, Luis Barrales, Alejandro Moreno, Guillermo Calderón, han sido exponentes de una producción textual que elude las formas del realismo. Sin embargo, en la última década, el trabajo escritural de Elisa Zulueta y la producción dramática de Gerardo Oettinger constituyen la representación de parte de las propuestas realistas actuales en un tiempo en que esta estética no es dominante. Así, ante estos procesos de transformación histórica de la producción dramática chilena, los dramas que Gerardo Oettinger escribe para la Compañía Teatro Síntoma (Bello futuro, La Victoria y Unidad Popular) forman parte de un pequeño grupo de textos que constituyen una excepción en las tendencias de la segunda década del siglo XXI.

El realismo en Bello futuro y La Victoria se manifiesta formulando una plasmación de los rasgos de un tiempo mediante la inclusión de personajes que participan de los conflictos propios del tiempo referido por la ficción. Es decir, los dramas de Oettinger construyen una representación con carácter histórico. Esto es posible porque, siguiendo la explicación de Lukács sobre la potencialidad de que los textos literarios formulen una representación histórica, para quien lo específicamente histórico es "el derivar de la singularidad histórica de su época la excepcionalidad 
en la actuación de cada personaje"10. De esta forma, los textos tendrían el potencial de generar la ilusión de que reproducen la realidad mediante la conformación de un reflejo artístico que buscaría tener la potencialidad de explicar los procesos sociales del transcurso histórico.

En Bello futuro, las integrantes del taller de costura forman parte del sector de la sociedad que ha sido oprimido por la dictadura militar. Se trata de mujeres pobres que viven en una población periférica de la ciudad de Santiago y que experimentan el alcance de las redes que la dictadura despliega en todos los rincones de la sociedad para dar forma a la estructura de poder. Estas mujeres, pese a no estar de acuerdo con su experiencia bajo el orden dictatorial, actúan subordinadas a la imposición de las relaciones de poder al interior de la estructura social construida por el régimen. En el siguiente fragmento, las integrantes del taller manifiestan su disconformidad ante la situación nacional:

Fresia: (...) Yo vi a un niño morir de hambre. La madre no tenía leche. La guagua duró dos meses. Fue terrible. La Gema nunca más se recuperó de eso, perder a un hijo así, a un angelito inocente. El hambre no se la doy ni a mis peores enemigos.

Myrna: (...) A la vieja culiá le tiraría una maldición pa que se muera sola, pasá a pichí y a caca, y que sus nietos, y sus tataranietos se avergüencen de haber nacío de esa sangre. ${ }^{11}$

Ester: Quién más que yo pa odiar a todos esos mal nacíos, pero no podemos perder la pega y que nuestra familia pase hambre, hay que pensar, y esperar a que el plazo se cumpla, en algún momento el caballero se va a tener que ir. La paciencia es una planta amarga que da frutos dulces. ${ }^{12}$

Pese a la disconformidad, las mujeres no tienen más opción que aceptar las circunstancias nacionales. Ester, por ejemplo, acepta la presión de tiempo que exige el taller de costura: "Ya paremos la lengua, y pongámonos las pilas, y voh deja de comer miera, estamos re atrasás con la meta pa fin de año, y nos queda menos de un mes"13.

En La Victoria, las integrantes de la olla común en la población La Victoria también son oprimidas por la dictadura. Se trata, en este caso, de mujeres pobres que se enfrentan a los efectos de la desigualdad social mediante la unión que implica

10 Georg Lukàcs, La novela histórica, Jasmín Reuter trad. (Ciudad de México: Ediciones Era, 1996), 15.

11 La expresión coloquial "vieja culiá" refiere a Lucía Hiriart, esposa del dictador Augusto Pinochet.

12 Gerardo Oettinger, Bello futuro (Santiago: [texto no publicado]. Estreno en el Teatro Universidad Mayor, 2013), 7.

13 Ibídem. 
cocinar para toda la comunidad. A diferencia de las mujeres de Bello futuro, las de La Victoria parecen mantener una postura beligerante contra la dictadura, como se demuestra en el siguiente fragmento:

Brígida: ¿Qué pasó con la harina?

Yolanda: Un gurka la meó, mientras otro se quedó apuntándonos con su metralleta.

Lidia: Los perros culiaos. En esta cagá de patria no hay justicia, mearse en la comía. Habrase visto tanta insolencia.

Nora: Los boinas negras andaban en operación peineta, buscando elementos subversivos, armas, carteles, panfletos, todo lo que tuviera que ver con la Marcha del Hambre.

Brígida: Pero, ¿cómo fue que pudieron entrar?, si a la capilla no se metían estos desgraciaos. Si hasta le tienen miedo al poder de la monja.

Inés: Como la monja no estaba se aprovecharon poh. Estos sinvergüenzas le perdieron el respeto hasta a la santidá.

Nora: Pero los perros estos no se las llevaron na pelá, igual les hicimos la collera, nos resistimos con las uñas y dientes.

Yolanda: Les dijimos que aquí la hermanita era la patrona, la dueña e' casa, que ningún régimen se iba a meterse en su hogar sin su consentimiento ${ }^{14}$.

El texto muestra cómo las mujeres se opusieron al allanamiento, pero también muestra que en la población se realizaban actividades que buscaban combatir al régimen. Por un lado, se señala que se está organizando la Marcha del Hambre, como respuesta a la miseria en que viven las pobladoras y sus familias, y la experiencia del hambre que caracteriza su constitución como sujetos marginales en el contexto de despliegue de un modelo económico capitalista. Pero el fragmento sugiere, también, que los carabineros buscaban armamento con los que algunos miembros de la población habrían participado del enfrentamiento con la fuerza policial, explicitándose asimismo la disidencia de los personajes con respecto al régimen militar.

De esta forma, ambos dramas incluyen a los partícipes del conflicto social que mayormente caracteriza las relaciones de poder al interior de la estructura social en las décadas de los setenta y los ochenta en la historia de Chile. En ambas obras, por tanto, el conflicto que rige las relaciones de poder en el Chile dictatorial es referido mediante su despliegue en los pequeños espacios sociales. Así, el taller de costura y la olla común en los dramas de Oettinger funcionan como metonimias del conflicto social que participa de la constitución de los rasgos característicos de la estructura de poder desplegada por la dictadura chilena, pues el taller de costura y la olla 
común presentan, a nivel local, la violencia cultural que, a nivel global, caracteriza a la sociedad chilena y que produce, como se explicará más adelante, marginalidad económica y política.

En síntesis, es mediante la constitución de estas metonimias que Bello futuro y La Victoria formulan juicios sobre el despliegue de tal estructura de poder. Es, probablemente, a causa de la formulación de estos juicios que se vuelve necesario en los dramas de Oettinger la articulación de estas metonimias que se traducen en la conformación de textos realistas. Así, la elección estética en los dramas de Oettinger se relaciona estratégicamente con la construcción de sentido.

\section{Fenomenología del hambre}

El hambre es la experiencia de los oprimidos de una sociedad. Tal experiencia moviliza a quienes la padecen a actuar para buscar la sobrevivencia propia y de los miembros de la comunidad. Esta acción rompe la cotidianeidad en el espacio comunitario que habitan estos oprimidos y en su inmanencia reflexiva derivada de tales acontecimientos, surge el sacrificio como opción o riesgo ante la búsqueda de la mencionada sobrevivencia. La experiencia del hambre aparece en los dos dramas de Oettinger aquí estudiados con el propósito de dar forma a nuevas maneras a través de las cuales, en la historia de Chile, se construye marginalidad económica y política en una sociedad patriarcal que siempre ha producido marginación a nivel de género. Esta discusión propicia que, en la estrategia discursiva de los dramas, quienes ejercen la rebelión ante la estructura de poder sean mujeres.

En primer lugar, la variante de la marginalidad económica construida como imagen en los dramas de Oettinger se sitúa en las décadas de los setenta y ochenta, y se articula desde la implementación de una modalidad de producción económica sostenida en el pensamiento neoliberal. Esto propicia un tránsito desde la lógica económica desplegada en gran parte del siglo XX (un capitalismo con un cierto Estado benefactor) hacia un capitalismo en que todas las instancias están regidas por las leyes del mercado. El impacto de la implantación de este modelo económico por parte del proyecto refundador de Chile impuesto por la dictadura de Pinochet produce esta forma de marginalidad económica, al propiciar una economía que busca el crecimiento y la estabilidad global mediante la implantación de una estructura desigual que produce la tradicional oposición binaria de sujetos centrales y marginales, ahora regulada desde nuevos parámetros económicos. La misma olla común y las alusiones a la Marcha del Hambre en La Victoria participan de la representación de este fenómeno social en la estrategia del drama. Por su parte, la alusión a la muerte de un niño por la falta de comida en Bello futuro forma parte de la misma intención discursiva. 
En relación con esto, los dramas de Oettinger no incluyen en sus juicios una valoración que indique que alguna etapa de desarrollo del capitalismo en la historia de Chile fue mejor que la otra, sino que buscan explicar cómo la lógica económica impuesta en el tiempo referido por las ficciones, al constituirse como un nuevo modelo que inaugura una nueva época en la historia de Chile, actuaría como el origen de la lógica económica que rige el país en el tiempo de estreno de las obras. La consideración de estas ideas a partir de la lectura de las estrategias discursivas que proponen los dramas de Oettinger ofrece la posibilidad de pensar la constitución de la marginalidad económica en la historia reciente de Chile. De este modo, en la imagen de la historia de Chile que articulan los dramas de Oettinger es posible observar que la experiencia del hambre es el primer efecto de la marginalidad económica y, a su vez, es el motor para que, desde la parte alta de la estructura de poder, se vuelva necesario apuntalar la violencia de Estado que da forma a la marginalidad política.

En gran medida, la condición marginal de las protagonistas no está dada por la ubicación geográfica donde habitan, o por el trabajo que desempeñan, sino más bien por el tipo de relación asimétrica sostenida entre ellas y los aparatos represivos de la dictadura. Como se ha advertido, la marginalidad en que viven las mujeres que participan de la acción en los dramas Bello futuro y La Victoria es de carácter económico, pero a la vez, dada la estructura política existente en las décadas de 1970 y 1980 que moviliza la refundación de Chile, esta marginalidad económica es movilizada por la articulación de una modalidad de producción económica que responde a un proyecto político: la instauración del neoliberalismo. El hecho de que esta transformación en las modalidades de producción de la vida material se lleve a cabo mediante la fuerza, produce que quienes se constituyen como marginales económicos durante este tiempo sean, a la vez, marginales políticos. El sector de la comunidad nacional que es relegado al margen por quienes ejercen el poder desde el centro no puede ejercer una resistencia eficiente ante la lógica jerarquizadora que se está imponiendo porque está siendo permanentemente violentado. $\mathrm{Al}$ respecto, Margarita, apodada la Coneja, señala: "La directiva está muy orgullosa de su trabajo, pero el voluntariado dice que a las finales se presta pa puro copushenteo y perder el tiempo, y se propicia para que se les suelte la lengua, y empiecen con los pelambres, ya he pillao a varias hablando mal del CEMA y del Gobierno"15.

Esta situación de convivencia al interior de los talleres de CEMA-Chile expone la necesidad del régimen de mantener controlados a quienes se le oponen. Antes, Ester había dicho sobre la Coneja: "Es parte de la directiva y estamos cagá" ", a lo que Luisa agrega: "Capaz que nos mande a los pacos por habladoras"17. Aunque

\footnotetext{
15 Oettinger, Bello futuro, 12.

16 Ibíd., 7.

17 Ibídem.
} 
la violencia del régimen no se manifieste de manera explícita, ésta está sugerida en el temor que sienten las integrantes del taller y en la condición de pobreza que puede, incluso, ser peor si fuesen expulsadas de la agrupación. En La Victoria, en cambio, la violencia del gobierno se manifiesta directamente en el conflicto que guía la acción dramática. Después de que la policía ha ingresado a la iglesia y arruinado los ingredientes para la olla común, Nora dice que "es obvio que los chanchos van a volver po, si no son na' tontos"18, ante lo cual Brígida contesta: "Si vienen de nueo, les ponemos el pecho a las balas" ${ }^{19}$. La pobreza y el hambre, por tanto, son productos de una estructura de poder económica que busca ser validada, por un lado, y de un sistema político que violenta, mediante la coacción, a quienes pudieran oponerse a la implantación del modelo económico, por el otro.

En Bello futuro, el taller de costura de CEMA-Chile se articula en torno al objetivo de otorgar trabajo a las mujeres de las familias de la clase baja de la sociedad chilena. En este contexto, las mujeres sostienen el siguiente diálogo:

Myrna: Y en la radio y en la tele sale que el CEMA paga todo, pero no está siendo na así como dicen.

Margarita: Eso es para las personas de escasos recursos, de extrema pobreza Ester: Pero nosotras también estamos escasas de recursos.

Luisa: Estamos casi al laíto de la extrema pobreza.

Margarita: Pero no somos na de extrema, extrema pobreza

Fresia: ¿Y qué es la extrema pobreza?

Margarita: No preguntí weás ${ }^{20}$.

Las costureras del taller manifiestan su escasez de recursos, pero la encargada justifica la ausencia de insumos negando la pobreza de las integrantes. Pero además de justificar que el gobierno no debe ofrecerles los insumos gratis porque no son lo suficientemente pobres, Margarita busca construir la imagen de que ellas, al ser miembros del taller de CEMA-Chile, están mejor que otras familias y cada vez que ellas intentan demostrar con argumentos que efectivamente son pobres, la representante del gobierno las acusa de estar ideologizadas negando la posibilidad de que sus argumentos puedan ser esgrimidos. En relación con esto, Ester dice: "Los hombres están casi todos cesantes, y los trabajos de empleo mínimo y el POJH pagan un tercio del sueldo mínimo"21, ante lo cual Margarita contesta: "Veí que te pasai pa la punta? (...) Por eso se prohibieron los tecitos porque se presta pa puro pelar el shansho" "22. Tal como se muestra en estas citas, se trata, además, de mujeres

Oettinger, La Victoria, 16.

Ibídem.

Oettinger, Bello futuro, 15.

Ibídem.

Ibídem. 
que cumplen estas funciones productivas en un contexto de aumento de la cesantía, lo que debido al carácter patriarcal de la sociedad chilena, propicia que las mujeres deban suplir a los hombres en la búsqueda de ingresos familiares.

Las ganancias en el taller de costura son insignificantes y el trabajo es excesivo. La institución se muestra a sí misma como un ejemplo de integración de la mujer al mundo laboral y como salida desde el espacio privado (al que ha sido hasta ahora confinadas por la sociedad patriarcal) hacia el espacio público de la producción económica. Sin embargo, se trata más bien de la instauración de la explotación laboral y la naturalización de la desigualdad social, ahora bajo nuevas modalidades de producción económica, guiada por ideas neoliberales y caracterizada por el cese del Estado benefactor y la instauración de una sociedad regida, en todos sus ámbitos, por las leyes del mercado. Esto fuerza a que las integrantes del taller de costura trabajen bajo condiciones de explotación (pues deben cumplir una exigente cuota de producción) y, a su vez, reciban a cambio una baja remuneración.

La desigualdad también se manifiesta en impedimentos para salir del taller o, incluso, para detenerse a tomar el té: "Estaban tomando té las porfiaitas"23, dice Margarita, a modo de recriminación. Tal como ocurre en un taller de costura privado, la organización de las trabajadoras se construye jerárquicamente. En esta estructuración, Margarita, la Coneja, recibe una cuota de poder que le permite estar por sobre sus compañeras; tiene atribuciones que sus compañeras no, y ejerce esa superioridad permanentemente. Por tanto, es también una mujer de clase baja que, en medio de las carencias, busca atenuar la fuerza de la pobreza. Sin embargo, ella representa al poder ausente y, en su ausencia, este poder se hace presente en ella, pues, como se señaló, las otras mujeres temen que ella pueda "mandar a los pacos". Dicho de otro modo, la Coneja, una pobladora cualquiera, consuma la figura de Pinochet en la población.

La presión que la Coneja ejerce sobre sus compañeras se ampara en el anuncio de la visita de Lucía Hiriart, esposa del dictador y presidenta de la fundación CEMAChile. Por tanto, se trata de la jefa de las trabajadoras de éste y todos los otros talleres de costura pertenecientes a la fundación. Además, al igual que la Coneja el resto del tiempo, Lucía Hiriart se constituye en su visita como la figura que encarna el poder de su esposo en este microespacio femenino de explotación. El anuncio de su visita es la confirmación de que el dominio de la dictadura es capaz de desplegar su poder e imponer su estructura en todos los ámbitos de la realidad social, lo que permite a su vez que su alcance total construya con rigurosidad los espacios centrales y los periféricos. La pobreza y el hambre, por tanto, son expresión de la articulación de ambas marginalidades, pues para la instauración de una modalidad económica que modifica lo que caracterizó el despliegue de la lógica capitalista en Chile durante todo el siglo XX, se requirió un proyecto político impuesto y caracterizado por 
el ejercicio de la violencia de Estado, especialmente porque el proyecto neoliberal se impone tras derrocar un intento de aproximación a un proyecto socialista: el gobierno de Salvador Allende entre 1970 y 1973.

En La Victoria, la olla común en la población tiene el propósito de combatir los obstáculos que la estructura económica ha impuesto ante la posibilidad de acceso a los alimentos. La necesidad de la olla común no es producto del desabastecimiento, sino de la distribución irregular de la riqueza del país. Esto propicia que, mientras la mayoría no puede adquirir satisfactoriamente el alimento, unos pocos no tengan problema en obtenerlo. Constituye una demostración simbólica de esto el hecho de que la estrategia discursiva del drama incluya en la acción una situación en que los miembros de la comunidad de La Victoria deben realizar un robo a un camión que traslada carne. Al respecto, Brígida dice "No nos hagamos los hueones. Lo hacen pa parar los camiones y robarlos. Ponen a una persona en la mitad de la calle, así, como si hubiera tenío un accidente"24. Es así como la carne, que está destinada a aquellos sectores de la sociedad chilena que ostentan algún poder de consumo, llega a los habitantes de las poblaciones marginales.

$\mathrm{Al}$ igual que en Bello futuro, en La Victoria son las mujeres de la población las encargadas de vencer los efectos del obstáculo económico impuesto por la nueva modalidad de producción de la vida material. Como rasgo común, la estrategia de La Victoria participa de la búsqueda explicativa del origen de la violencia que se ha articulado como rasgo de la cultura de la sociedad chilena. Es a partir de lo anterior que se da forma a la imagen de la marginalidad económica. Pero, como se ha señalado, la olla común ha sido saboteada por el ingreso a la población de los carabineros. Este ingreso tiene propósitos represivos, que se manifiestan en que el espacio de la iglesia donde se cocina para que toda la población pueda comer sea destruido por ellos, y la comida sea botada al suelo. Las mujeres, que en todo momento ostentan una conducta beligerante (que las diferencia inicialmente a la actitud subordinada de las mujeres de Bello futuro), se presentan en la estrategia discursiva del drama como el símbolo de las víctimas de la violencia de estado.

En relación con el heroísmo, éste se manifiesta en las costureras de Bello futuro en la decisión de incendiar el taller y no cumplir con la cuota establecida, y de esta forma, boicotear la visita de la esposa del dictador. Esto se ejemplifica en el momento en que Myrna manifiesta su cansancio: "Estoy cansá, ojalá se quemara toda esta weá pa que todo se termine de una vez por todas" ${ }^{25}$, ante lo cual Fresia responde: "Quememos la sede" ${ }^{26}$. El desenlace de la acción dramática sitúa a una de las costureras en el instante previo a la destrucción del taller. La realización de tal acontecimiento constituye su sacrificio para la obtención de la supervivencia de 
la comunidad, pues de esta forma se vence a la institucionalidad. La ocurrencia del sacrificio no está incluida en el tiempo de la acción con el propósito de que aquello que se presenta como inminente en la ficción se articule como un eventual triunfo que es contradictorio con la impresión que los receptores actuales tienen sobre lo que ocurrió en las siguientes décadas de la historia de Chile.

El heroísmo en La Victoria se manifiesta en la decisión de no poner fin al proyecto a través del cual las mujeres de la comunidad enfrentan el hambre pese a la muerte de la hija de una de las encargadas. La mujer, tras enterarse de que la víctima del atropello cuando robaban la carne del camión era su propia hija, retoma su labor en la olla común que busca beneficiar a la comunidad y relega su propia desgracia a segundo plano. Sobre esto Yolanda exclama: "iTe dije que no!, no voy a ir, no quiero verla, no ahora, no quiero verla" ${ }^{27}$, para luego agregar: "La muerte de mi hija no va a ser en vano, así que terminémosla. No por na le pusimos a esta olla la Victoria" ${ }^{28}$. Así la acción dramática llega a su fin. No se sabe qué sucede después, pero la estrategia dramática del texto sugiere que, al menos ese día, en la población La Victoria sí hubo qué comer. Este eventual triunfo, al igual que en Bello futuro, es contradictorio con la impresión que los receptores actuales tienen sobre la articulación de la desigualdad en la historia reciente de Chile.

En la segunda década del siglo XXI, estos dramas construyen una imagen de la violencia de la vida material producida en el contexto dictatorial. El propósito de contemplar de manera analítica el pasado mediante las potencialidades de la ficción dramática es reflexionar y juzgar los procesos históricos de los cuales deriva el Chile de hoy. Los dramas de Oettinger ofrecen, así, una imagen del origen de la implantación de la desigualdad como rasgo cultural de la sociedad chilena en el tiempo en que la lógica capitalista ha transitado desde su sustento liberal al llamado neoliberal. Al hacer referencia a la violencia como una manifestación cultural, se ha postulado que la violencia es un rasgo cultural de la sociedad chilena. Por lo tanto, en el ejercicio de lectura crítica de los dramas de Oettinger se buscó demostrar que la acción dramática de ambas obras muestra que las relaciones de poder que participan de la conformación de la cultura chilena en dictadura y en la postdictadura se despliegan mediante la realización de la violencia.

Dicho de otro modo, la violencia es un rasgo cultural que ha participado de la articulación de la estructura de poder. Para comprender el uso que se le ha dado al concepto cultura, son útiles las ideas formuladas por Raymond Williams. Este teórico culturalista se pregunta “'¿Somos capaces de entender 'cultura' como 'las artes', como 'un sistema de significados de valores', o como una 'forma de vida'?; y ¿cómo estas definiciones se relacionan con la 'sociedad' y la 'economía'?’’29. En

27 Oettinger, La Victoria, 70.

$28 \quad$ Ibíd., 71.

29 Raymond Williams, Marxismo y literatura, Guillermo David trad. (Buenos Aires: Las Cuarenta, 2009), 22. 
su explicación, Williams señala que "la idea de un proceso social fundamental que configura 'modos de vida' específicos y distintos, es el origen efectivo del sentido social comparativo de 'cultura' y sus ahora necesarias 'culturas' plurales" ${ }^{\prime 30}$. En su reflexión historicista y dialéctica, Williams advierte que hubo tiempos en que se manifestó una resistencia a entender cultura como "un proceso constituyente de lo social, creador de específicas 'formas de vida' que podrían haber sido profundizadas notablemente por el énfasis puesto en el proceso social material" ${ }^{\prime 31}$. Al explicar esta negación histórica a este uso del concepto cultura, el autor está proponiendo que esta es una manera coherente de comprenderlo.

Aunque los dramas de Oettinger fueron escritos algunos años previos al estallido social de 2019, es posible comprender que la violencia como rasgo cultural en el despliegue de las relaciones de poder en la realidad social chilena (manifestado en violencia de clase, de etnia y de género) ha sido el motor de este levantamiento popular en contra de la desigualdad social.

Como parte de este marco histórico que permite comprender el relato del Chile dormido que hoy despierta, es necesario decir que la cultura chilena está mediada por la naturalización de la violencia en el ejercicio de las relaciones de poder. Dicho de otro modo, en el Chile democrático de los últimos 29 años, un segmento del sector oprimido dejó de percibir su condición de oprimido porque se encontraba anestesiado por la falsa sensación de satisfacción que propició la lógica económica creada por la dictadura y perpetuada en democracia. En estos años, mientras la modernización ocurría ante nuestros ojos y los chilenos nos embriagábamos por el mayor poder adquisitivo mediado por el endeudamiento, cierto sector de la clase oprimida comenzó a modificar sus rasgos identitarios. Los hijos (primera generación de universitarios) nos creímos mejores que nuestros padres y los chilenos nos creímos mejores que nuestros vecinos. A la vez que disminuía la pobreza y el desempleo, y la ciudad se llenaba de edificios y centros comerciales, la sociedad chilena de los últimos años del siglo XX avanzó hacia la despolitización de sus preocupaciones. La puerta quedó abierta para el chauvinismo y la xenofobia, y la identidad chilena se saturó de autocomplacencia. Chile entró en un profundo sueño ${ }^{32}$.

En este contexto, los dramas de Oettinger explicarían la instauración de la violencia como rasgo cultural aún en la dictadura. De esto se desprende que el actual estallido social encuentre su origen en la violencia cultural de la dictadura perpetuada en la postdictadura. Como parte de la instauración de la violencia como rasgo cultural de la sociedad chilena, la dictadura despliega la violencia en

Williams, Marxismo y literatura, 28.

Ibíd., 31.

Estas ideas se encuentran también en Federico Zurita, “Chile despertó: cómo tres décadas dormidas explican el estallido", Eduvim, 29 de octubre de 2019, consultado en diciembre de 2019, disponible en https://www.eduvim.com.ar/blog/chile-desperto-como-tres-decadasdormidas-explican-el-estallido. 
todos los espacios posibles de conformación social. Entre estos se puede incluir a los originados espontáneamente para combatir los efectos de la dictadura (como la olla común que aparece en el drama La Victoria) y a los creados por las políticas de control dictatorial (como el taller de costura que aparece en Bello futuro). A estos pequeños espacios de control se les ha denominado microespacios en esta investigación, pues constituyen pequeños núcleos de conformación social hasta donde es posible que llegue la articulación de la violencia estatal. Desde esos espacios se comienza a construir la derrota en la que cae la sociedad chilena que, mediante la sensación de falsa satisfacción producida en la postdictadura, no reconoce inmediatamente. Pero es precisamente esa derrota la que explica las movilizaciones sociales de 2019. En relación con esto, los dramas de Oettinger, ya desde antes del estallido social, construyen su propuesta discursiva desde el reconocimiento de la existencia de esta derrota.

Como parte de las estrategias discursivas de estos dramas, sus formas, propias de la estética realista, han recurrido al ejercicio de ilusión de realidad sumado al de la conformación de un referente histórico explícito: la dictadura cívicomilitar. Pero además, la estrategia discursiva ha incluido a heroínas que, determinadas por la experiencia del hambre, llevan a cabo acciones beligerantes que trascienden las posibilidades de ocurrencia del referente histórico. Es decir, pese a que un gran sector de la sociedad chilena actuó oponiéndose a las imposiciones de la dictadura, el modelo económico implantado por ésta se instaló satisfactoriamente para los intereses de los asesores civiles de la dictadura: los Chicago Boys del nuevo Chile neoliberal. En ambos dramas, por tanto, el sacrificio de las mujeres parece conducir a una victoria que no se ha concretado en la realidad extratextual que constituye la historia de Chile. La impresión en los actuales auditores, lectores o receptores se completaría entonces al constatar, en los juicios derivados de la discusión a la que guían estos dramas, que la victoria no se concretó y que el bello futuro no logró realizarse. 


\section{Referencias bibliográficas}

Butler, Judith. Vulnerability in Resistance. Durham: Duke University Press, 2016.

Foucault, Michel. Microfisica del poder. Julia Varela y Fernando Álvarez-Uría traductores. Madrid: Las Ediciones de La Piqueta, 1980.

Galtung, Johan. "Cultural Violence”. Fournal of Peace Research 27, no. 3 (1990): 291305.

Lukács, Georg. "Realism in the Balance." En The Norton Anthology of Theory and Criticism, Vincent B. Leitch editor, 1033-1058. Nueva York: W. W. Norton \& Company, 2001.

. La novela histórica. Jasmín Reuter traductora. Ciudad de México: Ediciones Era, 1996.

Murphy, Ann V. "The Will to Live and the Meaning of Life: Hunger as Vulnerability in French Existential Phenomenology". Fournal of the British Society for Phenomenology 49, no.3 (2018):193-204.

Oettinger, Gerardo. Bello futuro. Manuscrito no publicado. Estreno en Teatro Universidad Mayor, 2013.

. La Victoria. Santiago: Das Kapital Ediciones, 2014.

Salamon, Gayle. "Here Are the Dogs: Poverty in Theory". Differences: A Fournal of Feminist Cultural Studies 21, no. 1 (2010):169-177.

Williams, Raymond. Marxismo y literatura. Guillermo David traductor. Buenos Aires: Las Cuarenta, 2009.

Zurita, Federico. "Chile despertó: cómo tres décadas dormidas explican el estallido". Eduvim, 29 de octubre de 2019. Consultado en diciembre de 2019, disponible en https://www.eduvim.com.ar/blog/chile-desperto-como-tres-decadasdormidas-explican-el-estallido.

Recibido: 22 de marzo de 2019

Aceptado: 27 de junio de 2019

\section{Sobre los autores}

Bernardo Rocco Núñez. Profesor de Literatura en la Universidad Alberto Hurtado (Santiago, Chile). Doctor en Literatura con mención en Literatura 
Chilena e Hispanoamericana por la Universidad de Chile. Correo electrónico: stereohead73@gmail.com.

Federico Zurita Hecht. Profesor de Literatura de la Universidad Finis Terrae (Santiago, Chile). Doctor en Literatura con mención en Literatura Chilena e Hispanoamericana por la Universidad de Chile. Correo electrónico: fzurita@uft.cl. 